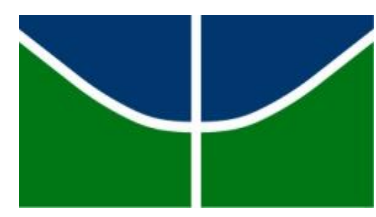

UNIVERSIDADE DE BRASÍLIA

Faculdade de Educação - UAB/UnB/ MEC/SECAD

Curso de Especialização em Educação na Diversidade e

Cidadania, com Ênfase em EJA

MARIA DE FÁTIMA NERY DA SILVA CRUZ

\title{
A EDUCAÇÃO DE JOVENS E ADULTOS NA CONSTRUÇÃO NOS PRINCÍPIOS DA CIDADANIA
}

BRASÍLIA, DF

Julho/ 2010 
UNIVERSIDADE DE BRASÍLIA

Faculdade de Educação - UAB/UnB/ MEC/SECAD

Curso de Especialização em Educação na Diversidade e

Cidadania, com Ênfase em EJA

\section{A EDUCAÇÃO DE JOVENS E ADULTOS NA CONSTRUÇÃO NOS PRINCÍPIOS DA CIDADANIA}

MARIA DE FÁTIMA NERY DA SILVA CRUZ

ELIZABETH DANZIATO REGO

AIRAN ALMEIDA DE LIMA

PROJETO DE INTERVENÇÃO LOCAL (PIL)

BRASÍLIA, DF JULHO /2010 
UNIVERSIDADE DE BRASÍLIA

Faculdade de Educação - UAB/UnB/ MEC/SECAD

Curso de Especialização em Educação na Diversidade e

Cidadania, com Ênfase em EJA

MARIA DE FÁTIMA NERY DA SILVA CRUZ

\section{A EDUCAÇÃO DE JOVENS E ADULTOS NA CONSTRUÇÃO NOS PRINCÍPIOS DA CIDADANIA}

Trabalho de conclusão do Curso de Especialização em Educação na Diversidade e Cidadania, com Ênfase em EJA, como parte dos requisitos necessários para a obtenção do grau de Especialista na Educação de Jovens e Adultos

\section{ELIZABETH DANZIATO REGO}

PROFESSOR ORIENTADOR

AIRAN ALMEIDA DE LIMA

TUTOR ORIENTADOR

ROGÉRIO DE ANDRADE CÓRDOVA

AVALIADOR EXTERNO

BRASÍLIA, DF JULHO / 2010 
"A educação é um ato de amor e, portanto um ato de coragem. Não pode temer o debate, a análise da realidade; não pode fugir da discussão criadora, sob pena de ser uma farsa"

(Paulo Freire) 


\section{RESUMO}

Este PIL tem como principal objetivo que o aluno da EJA, compreenda os princípios da cidadania e que tenha consciência da importância na sua formação de sujeito de ação, por meios de reflexões e questionamentos. As atividades dinâmicas e sociais serão incentivos para que o aluno possa expandir seu conhecimento, oportunizando a sua compreensão de cidadão como sujeito que participa e que também faz a diferença. 


\section{SUMÁRIO}

1. Dados de Identificação do proponente................................... 7

2. Dados de Identificação do Projeto........................................... 7

3. Ambiente Institucional .............................................................. 8

4. Justificativa e caracterização do problema................................... 8

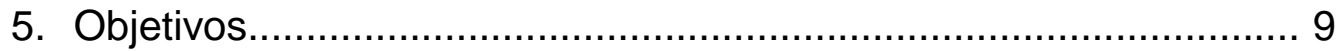

6. Atividades/ responsabilidades.......................................... 9

7. Cronograma.................................................................... 10

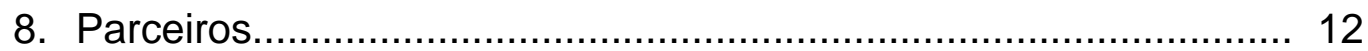

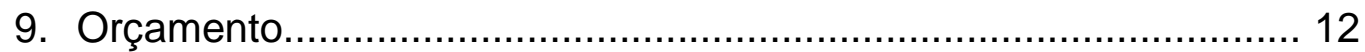

10. Acompanhamento e Avaliação................................................... 12

11. Referências...................................................................... 12

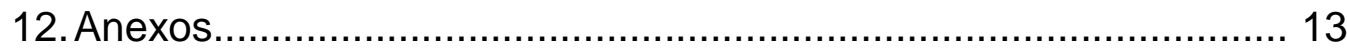




\section{Projeto de Intervenção Local:}

A educação de Educação de Jovens e Adultos na construção da cidadania.

1- Dados de identificação:

1.1- Nome: Maria de Fátima Nery da Silva Cruz

1.2- Turma: E

1.3- Telefone: (61) 35671217

(61) $32020331 \quad$ E-mail: fatimanscruz@gmail.com

\section{2- Dados de Identificação do Projeto:}

\section{1- Título:}

A educação de Jovens e Adultos na construção da cidadania

\section{2- Área de abrangência: Local}

O projeto tem intenção de abranger primeiro ás salas de aula especificamente da EJA, depois a instituição como um todo, podendo se estender para um nível de interesse maior.

\section{3- Instituição}

CEL- Centro Educacional do Lago- SHIS 09 Área Especial Lote "H”, Lago Sul Brasília-DF CEP: 71625-100

Telefone: $3901-2635$

Escola Pública da Secretaria de Estado e Educação do Distrito Federal (SEEDF) Diretoria Regional de Ensino Plano Piloto e Cruzeiro (DREPP/C)

\section{4- Público ao qual se destina:}

O público ao qual se destina são moradores e trabalhadores das comunidades de São Sebastião, Paranoá e Lago Sul. O público alvo é oriundo de um contexto de defasagem idade-série, sendo que alguns educandos têm aversão à escolarização em conseqüência de um quadro de multirrepetência e fracasso escolar. Dessa forma, diagnosticar os entraves impeditivos do sucesso educacional e social desses alunos requer, dentre outros, que se identifique essas experiências prévias, ressignificando suas expectativas de (re)inserção profissional e social.

\section{5- Período de execução:}

A partir do segundo semestre de 2010. 


\section{3- Ambiente institucional:}

Em 16 de agosto de 1979, foi inaugurado o Ginásio do Lago (GILA) que veio para atender à demanda de escolas pública no Lago Sul, visando principalmente os filhos de empregados deste local. Com o passar dos anos, o crescimento das comunidades de São Sebastião e Paranoá transformou o GILA em CEL (Centro Educacional do Lago). Os objetivos estabelecidos pelo Centro Educacional do Lago, visam à formação do educando em suas várias dimensões: a intelectual, a emocional, a criativa, a reflexiva e a crítica, para que ele possa alcançar pleno exercício da cidadania, dando-lhes a oportunidade de aprender a administrar problemas e conflitos pacificamente e de conviver solidariamente, enquanto cidadão crítico e capaz de transformar a realidade em que atua.

O Centro Educacional do Lago (CEL) possui nove salas de aulas, dois laboratórios, uma sala de vídeo, uma biblioteca, uma secretaria, uma sala de professores, uma sala de mecanografia, uma sala de coordenação, duas salas para direção/assistência, uma cantina e quatro banheiros, sendo dois para alunos (masculino/feminino) e dois para professores (masculino/feminino) e possui uma quadra de esportes descoberta, área verde e estacionamento.

No CEL, funcionam os três turnos: no diurno a escola atende alunos do ensino fundamental $7^{\mathrm{a}}$ e $8^{\mathrm{a}}$ séries e ensino médio $1^{\circ}, 2^{\circ}$ e $3^{\circ}$ ano; no noturno atende o $1^{\circ}$ e $2^{\circ}$ segmentos da EJA e o ensino médio regular $1^{\circ}, 2^{\circ}$ e $3^{\circ}$ ano.

\section{4-Justificativa e caracterização do problema:}

O ser humano tem características diversas e uma complexidade de natureza curiosa. As diferenças formam uma sociedade que enriquecem toda às áreas de aprendizagem. Para uns são as dificuldade do dia a dia, para outros apenas uma forma diferente de ver as coisas. O educando da EJA, com sua diversidade tem a necessidade de ter a sua participação nesse mercado de conhecimento. Essa necessidade poderá leválos a refletir, questionar ou até mesmo oportunizando a sua compreensão de cidadão como sujeito que participa e que também faz a diferença. 


\section{5- Objetivos:}

\section{1- Objetivo Geral:}

- Compreender a cidadania, conscientizando-se da sua importância por meios de reflexões e questionamentos.

\section{2- Objetivos específicos:}

- Compreender a importância do cidadão com sujeito de direitos e deveres;

- Motivar o aluno a perceber as mudanças que poderão auxiliar sua vida na busca do conhecimento;

- "questionar a realidade formulando-se problemas e tratando de resolvê-los, utilizando para isso o pensamento lógico, a criatividade, a intuição, a capacidade de análise crítica, selecionando procedimentos e verificando sua adequação." (PCNs 2001, p.7)

- Oportunizar, ao aluno, meios de demonstrar a aplicabilidade de seu aprendizado nas situações do cotidiano;

- Criar métodos que incentivem a percepção do aluno como sujeito de ação resgatando com isso sua auto-estima.

\section{6- Atividades/responsabilidades:}

As oportunidades tendem a serem de difícil compreensão no que tange o termo conhecimento. Ao aluno deve ser oportunizado um acesso de igualdade na sociedade; pois, só assim ele terá condições de refletir sobre o que é ser um sujeito de ação, um cidadão participativo, aquele que está e quer estar presente nas ações as quais possa compreender e decidir se deseja fazer parte. A escola se transforma na parceira ideal desse desenvolvimento intelectual que abrange o social, o emocional e moral. As atividades propostas tentam abrir um leque amplo, onde o próprio educando poderá expandir seu conhecimento e ver se encaixa na sua realidade, e também a liberdade de expressar o que adquiriu de experiência de vida em debates em sala. O projeto terá como um dos pontos principais:

- O comprometimento do aluno na escolha do material a ser trabalhado dandolhe condições de produzir outros materiais derivados desse trabalho;

- Aproveitamento da experiência e vivência crítica e criativa, permitindo-se a trabalhar com qualquer tema proposto dentro do projeto. 
- Com o trabalho e temas escolhidos pelo público alvo, juntos elaborar uma Carta de Intenções. Nessa carta serão expostas formas de dignificar o sujeito como cidadão participativo do cenário social e político do país.

Os Filmes: "O Caminho das Nuvens" de Vicente Amorim, "O poder de um jovem" de John G. Avildsen, "Rua da Paz" e "O imigrante" com Carlitos (Charles Charplin) serão como uma chave mestra para o aluno observar que a luta por direitos e deveres acontecem não somente no Brasil, mas também, pelo mundo afora e vem de muito tempo.

As músicas "Resposta" e "Pacato Cidadão" do grupo Skank, "A Estrada" e "Pensamento" do grupo Cidade Negra, poderão ser fonte de inspiração para os alunos poderem através das palavras expressarem suas dúvidas, críticas e questionamentos e até mesmo comporem algo de sua própria autoria.

Palestras com palestrantes que falem dos temas:

- Saúde (higiene corporal, higiene bucal, as DSTs, etc.): mostrar ao aluno que a saúde vem junto com o estar bem, que é um direito ter acesso a ela, como também dever do Estado proporcionar esse benefício dando acesso e dignidade as pessoas.

- Cidadania (identidade do sujeito, os direitos e deveres, etc.): mostrar ao aluno que ele pode transformar o cotidiano, e se transformar adaptando-se ao que lhe facilita a vida ou agir de forma que ele faça a diferença.

- Profissão (trabalho e emprego): dar uma idéia sobre o mercado de trabalho, a documentação necessária para fazer parte desse mercado, a importância da participação e interação, do estudo e das experiências em determinadas ares do mercado de trabalho.

\section{7- Cronograma:}

7.1- 24/08 e 31/08: - O filme "O caminho das Nuvens" como introdução do tema de cidadania num contexto de lutar por um sonho e se erguer a cada obstáculo que for surgindo no caminho das pessoas. A música "A Estrada" do grupo Cidade Negra como o pensamento do homem alcança distâncias inimagináveis e que podemos transformar esse pensamento com nossas ações para um bem comum a todos e que podemos fazer a diferença. Artigos com tema "Sou cidadão" o aluno destacará as diferenças do que acontece na atualidade e a luta que foi travada no passado para chegarmos onde estamos. 
7.2- 21/09 e 28/09: Tema: na Constituição Federal, Dos Direitos e Deveres Individuais e Coletivos, precisamente no Artigo $5^{\circ}$ diz o seguinte: “Art. $5^{\circ}$ Todos são iguais perante a lei, sem distinção de qualquer natureza, garantindo-se aos brasileiros e aos estrangeiros residentes no País a inviolabilidade do direito à vida, à liberdade, à segurança e à propriedade...": destacar o que o aluno entendeu no que se tange ao direito e dever do Estado e o que o cidadão pode fazer para compreender essas transformações que vão surgindo cada vez mais na sociedade atual e o que de benéfico ficou para o povo. A música "Resposta" do grupo Skank, visando o que a maior parte das pessoas desejam é ter respostas para a situação do sujeito da ação e o que se pode fazer para mudar esse quadro com tanta desigualdade no país, onde o acesso a educação não chega à todos. Palestra sobre Profissão (trabalho e emprego) com a participação de todos onde haverá uma interação entre o palestrante e o grupo de alunos.

7.3- 19/10 e 26/10: O filme "O Poder de um Jovem" a existência de diferenças onde deveria haver igualdade, a luta de um jovem pela liberdade de tocar o coração daqueles que se odeiam apenas por uma questão de cor de pele. $\mathrm{O}$ aluno poderá refletir sobre as desigualdades sociais com o tema "O muito para poucos, e pouco para muitos". A palestra sobre Cidadania (o sujeito com identidade própria, direitos e deveres, etc.) e outros temas de interesse do grupo que irá se interagir com o palestrante. A música "Pacato Cidadão" do grupo Skank, fala de ação e reação do ser humano, ficando estagnado perante as coisas que acontecem ao seu redor, e o aluno verificara o que pode ser feito se, o tão pacato cidadão, agir como um sujeito de ação. Será iniciada a elaboração da Carta de Intenção.

7.4- 09/11 e 23/11: A música "Pensamento" do grupo Cidade Negra será onde o aluno poderá fazer o uso de sua imaginação e criar uma música com todo o grupo, sendo coeso em suas palavras, para que os outros possam entender a mensagem que estão querendo transmitir. Os curtas de Charles Charplin "Rua da Paz" e "O imigrante" falam da luta e da adaptação a uma vida de faltas e excessos cometidos por nós e outros devido à aparência e situação social das pessoas. Continuação e fundamentação da "Carta de Intenção", para apresentação de um trabalho efetivado por todo o grupo. 


\section{8- Parceiros:}

Secretaria de Estado de Educação do Distrito Federal; Secretaria de Saúde do Distrito Federal; Secretaria do Trabalho e Secretaria de Direitos Humanos- Justiça e Cidadania, podendo ser acrescido de outros órgãos no decorrer do projeto

\section{9- Orçamento:}

Não é um projeto oneroso, já que só necessita de recursos humanos próprios e palestrantes que tenham conhecimento sobre o assunto. $\mathrm{O}$ material a ser utilizado serão o do cotidiano do aluno como revistas, livros, etc.

\section{0- Acompanhamento e avaliação:}

A avaliação será feita durante o processo do projeto, observando a participação de todos com críticas e reflexões relacionadas às atividades dadas e verificar a evasão de alunos ao final deste projeto.

\section{1- Referências:}

BRASIL. Constituição da República Federativa do Brasil, Título II, Capítulo I, Artigo 5, p. 13- Brasília: Senado Federal. edição 2007/2008.

BRASIL. Constituição da República Federativa do Brasil, Título VIII, Capítulo III, Seção I, Artigo 205, p. 136 e Artigo 208, p. 137- Brasília: Senado Federal. Ed. 2007/2008.

PINSKY, Jaime. PINSKY, Carla Bassanezi. História da cidadania. Conto: "O nascimento de um cidadão" texto de Moacyr Scliar, p. 585 - Ed. Contexto, São PauloSP, 2008.

BRASIL. Lei de Diretrizes e Bases da Educação Nacional. Lei Nº9394, 12/1996, Brasília- DF, 1996.

FREIRE, Paulo. Pedagogia da Esperança. $3^{a}$ edição, Ed. Paz e Terra, Rio de JaneiroR.J, 1998.

DISTRITO FEDERAL (Brasil). Secretaria de Estado de Educação. Currículo da Educação Básica das Escolas Públicas do Distrito Federal. 2ª edição, Ed. Brasília, 1998.

BRASIL. Secretaria de Estado de Educação. Parâmetros Curriculares Nacionais (PCNs). Secretaria de Educação: Ensino Fundamental p.7; Brasília: MEC/SEF, 2001.

HOBSBAWN, Eric. A Era dos Extremos: O breve século XX (1914-1991). Capítulo: Revolução Social, p. 298-314. Ed. Companhia das Letras. São Paulo-SP, 1997. 
ANEXOS 


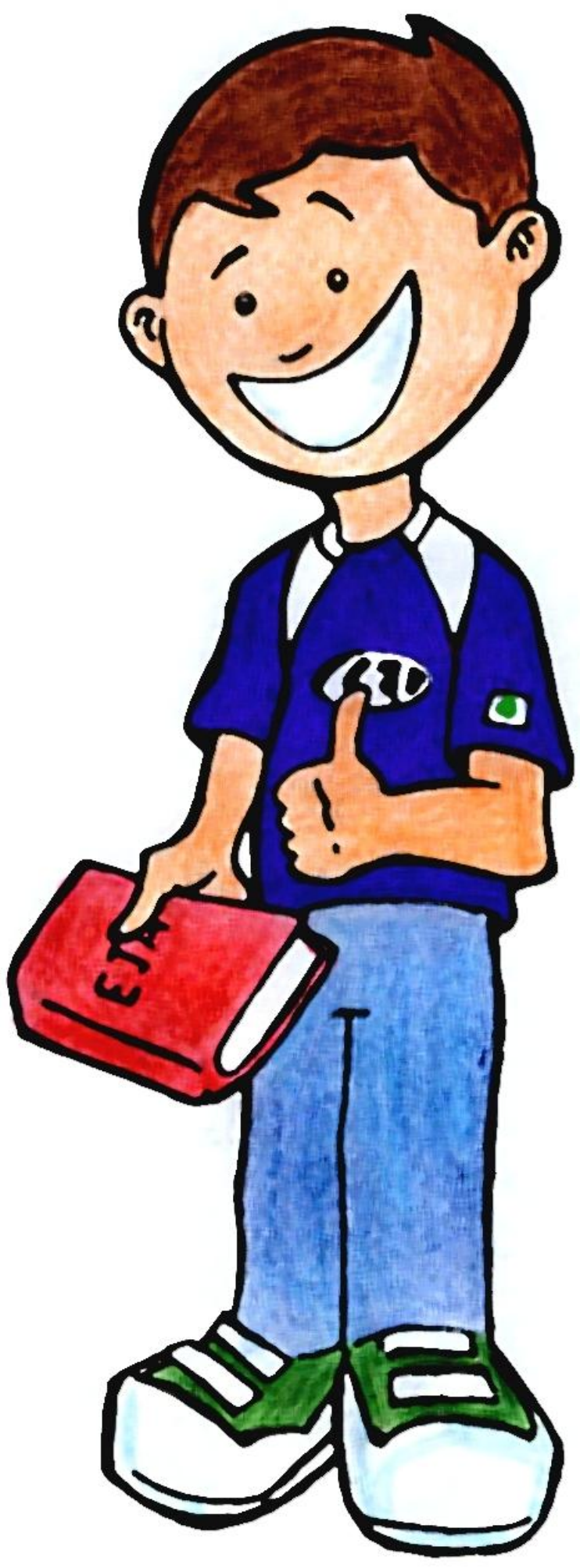

Mascote - Criado por Felipe Cruz da Costa. 


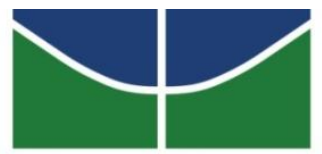

UNIVERSIDADE DE BRASílLIA

Faculdade de Educação -UAB/UNB/MEC/SECAD

Curso de Especialização em Educação na

Diversidade e Cidadania, com Ênfase em EJA

Maria de Fátima Nery da Silva Cruz - fatimanscruz@gmail.com

\title{
A Educação de Jovens e Adultos na Construção nos Princípios da Cidadania
}

\author{
Centro Educacional do Lago (CEL) \\ SHIS 09 Área Especial lote "H" - Lago Sul
}

\section{Ambiente Intitucional :}

Centro Educacional do Lago - CEL

\section{Justificativa e Caracterização:}

O educando da EJA, em sua diversidade tem a necessidade de ter a sua participação no mercado do conhecimento.Essa necessidade poderá levá-lo a refletir, questionar ou até mesmo oportunizar sua compreensão de cidadão como um sujeito que participa e que também faz a diferença.

Mostrar aos alunos da EJA os princípios da cidadania e a compreensão do ser cidadão como um sujeito de diteiros e deveres eque participa direta ou indiretamente das decisões sociais, políticas e econômicas do país

\section{Referências:}

BRASIL. Constituição da República Federativa do Brasil, Título II, Capitulo I, Artigo $5^{\circ}$, p. 13. Brasília; Senado Federal, Edição 2007/2008.

BRASIL. Constituição da República Federativa do Brasil, Título VIII, Capítulo III, Seção I, Artigo 205, p. 136 e Artigo 208, p. 137. Brasilia: Senado Federal, Edição 2007/2008.

BRASIL: Lei de Diretrizes e Bases da Educação Nacional. Lei n 9394, 12/1996. Brasília-DF, 1996.

BRASIL: Secretaria de Estado de Educação. Parâmetros Curriculares Nacionais (PCNs). Secretaria de Educação: Ensino Fundamental, p. 7; Brasília: MEC/SEF, 2007.

DISTRITO FEDERAL, Secretaria de Estado de Educação do. Currículo da Educação Básica das Escolas Públicas do Distrito Federal, $2^{\mathrm{a}}$ edição, Ed. Brasília, 1998.

FREIRE, Paulo. Pedagogia da Esperança. $3^{a}$ edição, Ed. Paz Terra, Rio de Janeiro-RJ, 1998.

HOBABAWN, Eric. A Era dos Extremos: o breve século XX (1914-1991) Capítulo Revolução Social, p. 298 - 314. Ed. Companhia das Letras, São Paulo-SP, 1997.

PINSKY, Jaime e Carla Bassanezi. História da Cidadania. Conto: O nascimento de um cidadão, texto de Moacyr Scliar, p. 585, Ed.Contexto, São Paulo - SP, 2008.

\section{Objetivo Geral :}

Compreender a cidadania, concientizando-se da sua importância por meios de reflexões e questionamentos.

\section{Período de Realização:}

A partir do $2^{\circ}$ semestre de 2010 .

\section{Atividades:}

- Palestras, filmes e músicas relacionadas ao tema;

- Trabalho de exposição individuais ou em grupo;

- Debates reflexivos e questionamentos;

- Elaboração de uma "Carta de Intenções". Parceiros:

Secretaria de Saúde do Distrito Federal (SSDF), Secretaria do Trabalho do Distrito Federal (STDF), UnB.

OBS: Poderão ser acrescidas outras parcerias no decorrer do projeto.

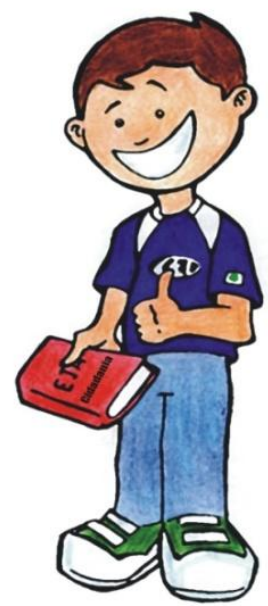

Banner de Apresentação - Criado por Felipe Cruz da Costa. 